and non-CSC based on designation by the Texas Department of State Health Services.

Results The number of AIS cases dropped substantially from 10,745 per quarter in the pre-pandemic period to 9,277 in the pandemic period $(-14 \%)$ in Texas. The percentage of patients aged younger than $65(39.0 \%$ vs $40.4 \%, \mathrm{p}=0.014)$ and LVO stroke $(30.0 \%$ vs $32.7 \%, \quad \mathrm{p}<0.001)$ slightly increased. Percentages of admission to CSC $(39.1 \%$ vs $39.5 \%, \mathrm{p}=0.57)$ and admission through inter-hospital transfer $(9.6 \%$ vs $9.3 \%, p=0.35)$ remained similar between pre-pandemic and pandemic periods. There was also no significant change in the use of IV-tPA $(14.1 \%$ vs $13.6 \%, \mathrm{P}=0.20)$ or EVT (5.4\% VS 5.8\%, P=0.12). In-hospital mortality slightly increased from $2.9 \%$ to $3.2 \%$ but it was not statistically significant $(p=0.13)$. However, the percentage of death or hospice discharge increased from $7.6 \%$ to $8.4 \%(p=0.003)$ and age and LVO type adjusted odds ratio was 1.13 (95\% CI 1.04-1.23).

Conclusion In this population-level study, significant decreases in AIS volume were observed with slightly higher incidence in younger population and higher LVO strokes. Rates of thrombolysis and thrombectomy remained unchanged but patients appeared to have worse outcomes.

Disclosures Y. Kim: None. S. Khose: None. S. Salazar-Marioni: None. R. Abdelkhaleq: None. S. Sheth: None.

\section{P-032 DISPARITIES IN STROKE: INFLUENCE OF SOCIOECONOMIC STATUS AND RACE ON TIMELY ACCESS TO MECHANICAL THROMBECTOMY}

AVT Nguyen, GM Cortez, M Baretta, A Aghaebrahim, E Sauvageau, R Hanel* Neurosurgery, Baptist Health System- Jacksonville, Jacksonville, FL

\subsection{6/neurintsurg-2021-SNIS.68}

Objective The present study aims to explore the influence of socioeconomic status (SES) and driving distance on timely access to mechanical thrombectomy.

Methods Patient data was collected retrospectively between 2016 and 2020 from a prospectively maintained database. Patients transferred from other facilities with driving distances of over 100 miles and onset-to-arrival (OTA) time and onset-to-puncture (OTP) time over 24 hours were excluded. Patient-level data included age, race, gender, median income based on zip code, driving distance, baseline dependency (mRS >2), baseline NIHSS scores, and wake-up stroke $\mathrm{y} / \mathrm{n}$. The driving distance was calculated using the Google Maps API, mapping distance between the center point of a zip code and the hospital's address. SES was defined by the zip code median income data from the 2019 U.S. Census Bureau's American Community Survey (ACS) 5-year Projection and patients' health insurance coverage. Primary outcomes OTA and OTP times, which were calculated by subtracting last-known-well time from arrival time and puncture time. We used a combination of nonparametric and multiple regression analyses to determine the predictors of outcome.

Results Among 305 patients collected, OTA time ranged from 9 to 1349 minutes, while OTP time ranged from 57 to 1422 minutes. Results demonstrated that race $(p<0.001)$, baseline NIHSS scores $(p<0.001)$, wake-up stroke $(p<0.001)$, and baseline mRS scores $(p<0.001)$ were all significantly associated with OTA and OTP time. Driving distance was significantly associated with OTA time $(\mathrm{p}=0.039)$ and OTP time $(p=0.005)$ as well. Median income, age, and gender did not exhibit any significant correlations.

Conclusions Race demonstrated to be an independent predictor of timely access to a stroke care facility and mechanical thrombectomy, while SES was not. Additional independent predictors were driving distance, wake-up stroke, and baseline functionality.

Disclosures A. V. T. Nguyen: None. G. M Cortez: None. M. Baretta: None. A. Aghaebrahim: 6; C; Advisory board for Rapid Medical. E. Sauvageau: None. R. Hanel: 2; C; Medtronic, Stryker, Cerenovous, Microvention, Balt, Phenox, Rapid Medical, Q'Apel. 4; C; InNeuroCo, Cerebrotech, eLum, Endostream, Three Rivers Medical Inc, Scientia, RisT, BlinkTBI, Corindus. 6; C; advisory board for MiVI, advisory board for eLum, dvisory board for Three Rivers, advisory board for Shape Medical, advisory board Corindus.

\section{P-033 DISPARITIES IN STROKE: ASSOCIATING PATIENT-LEVEL DEMOGRAPHIC FACTORS WITH LOSS OF FOLLOW-UP}

A Nguyen*, GM Cortez, M Baretta, A Aghaebrahim, E Sauvageau, R Hanel. Neurosurgery, Baptist Health System- Jacksonville, Jacksonville, FL

\subsection{6/neurintsurg-2021-SNIS.69}

Objective Loss of follow-up is a common barrier to achieving meaningful results in studies evaluating outcomes. In addition, lack of follow-up undermines the continuity of care that is crucial for ischemic stroke patients. Therefore, this study aims to explore feasible predictors and determinants of loss of follow-up in the ischemic stroke population, including socioeconomic status (SES) and various patient-level demographic factors.

Methods A retrospective review of a prospectively maintained database was performed between 2016 and 2020. Patient-level data collected include gender, age, race, traditional risk factors of stroke, and modified Rankin Score (mRS) at discharge. We measured SES using a combination of the zip code median income data from the 2019 U.S. Census Bureau's American Community Survey (ACS) 5-year Projection and patient health insurance coverage. Correlation between the rates of follow-up and demographic factors was analyzed using multivariate analyses.

Results Among 783 patients collected, 507 (64.7\%) came back for a 90-day follow up and 276 (35.3\%) did not. Our analysis demonstrated that there is a significant correlation between rates of follow up and race $(\mathrm{p}<0.001)$, discharge mRS ( $\mathrm{p}=$ $0.001)$, median income ( $\mathrm{p}=0.0001)$, and health insurance status $(\mathrm{p}=0.02)$. On the other hand, gender $(\mathrm{p}=0.82)$ and age $(\mathrm{p}=0.81)$ showed no significant correlation to follow up compliance. Furthermore, traditional stroke risk factors also demonstrated no significant correlation.

Conclusions Race, discharge mRS, median income based on zip codes, and health insurance coverage are potential determinants of whether an ischemic stroke patient who underwent thrombectomy would comply with a 90-day follow-up.

Disclosures A. Nguyen: None. G. M. Cortez: None. M. Baretta: None. A. Aghaebrahim: None. E. Sauvageau: None. R. Hanel: None. 